\title{
Measurements of Jaw Movements and TMJ Pain Intensity in Patients Treated with GaAlAs Laser
}

\author{
Marcelo Oliveira MAZZETTO ${ }^{1}$ \\ Takami Hirono HOTTA ${ }^{1,2}$ \\ Renata Campi de Andrade PIZZO ${ }^{1}$ \\ ${ }^{1}$ Ribeirão Preto Dental School, University of São Paulo, Ribeirão Preto, SP, Brazil \\ ${ }^{2}$ Dental School, University of Franca, Franca, SP, Brazil
}

\begin{abstract}
The aim of this study was to evaluate the effectiveness of low-level laser therapy (LLLT) on the improvement of the mandibular movements and painful symptoms in individuals with temporomandibular disorders (TMD). Forty patients were randomly divided into two groups $(\mathrm{n}=20)$ : Group 1 received the effective dose (GaAlAs laser $\left.\lambda 830 \mathrm{~nm}, 40 \mathrm{~mW}, 5 \mathrm{~J} / \mathrm{cm}^{2}\right)$ and Group 2 received the placebo application $\left(0 \mathrm{~J} / \mathrm{cm}^{2}\right)$, in continuous mode on the affected condyle lateral pole: superior, anterior, posterior, and posterior-inferior, twice a week during 4 weeks. Four evaluations were performed: E1 (before laser application), E2 (right after the last application), E3 (one week after the last application) and E4 (30 days after the last application). The Kruskal-Wallis test showed significant more improvements $(\mathrm{p}<0.01)$ in painful symptoms in the treated group than in the placebo group. A significant improvement in the range of mandibular movements was observed when the results were compared between the groups at E4. Laser application can be a supportive therapy in the treatment of TMD, since it resulted in the immediate decrease of painful symptoms and increased range of mandibular movements in the treated group. The same results were not observed in the placebo group.
\end{abstract}

Key Words: jaw movements, GaAlAs laser, articular pain.

\section{INTRODUCTION}

Temporomandibular disorder (TMDs) present signs and symptoms that affect the masticatory muscles, temporomandibular joint (TMJ) or both (1). The patient may report signs and symptoms such as muscle and TMJ pain (2), tenderness to palpation on the TMJ and face, restriction of mandibular movement and joint sounds (3).

The majority of patients suffering from TMD obtain relief of symptoms with different treatments (4). The use of low-level laser therapy (LLLT) for the treatment of musculoskeletal pain syndromes has become common (5-9) and the affected region is usually irradiated to cause attenuation of symptoms (10-12). LLLT presents biologic effects as increased pain tolerance due to changes in cellular membrane potency, vasodilatation, reduction of edema, increase in intracellular metabolism and acceleration of wound healing (13). The antiinflammatory (14), analgesic, and biomodulatory effects of lasers are recognized.

The gallium-aluminum-arsenide laser (GaAlAs) is an infrared ray with wavelength of $830 \mathrm{~nm}$ (15) that is used for treating a wide array of conditions (16) and its effect depends on dose application (17), target tissue, and immunological system conditions (18). This study evaluated the influence of GaAlAs $(\lambda 830 \mathrm{~nm})$ application in subjects with TMJ pain by palpation of the lateral pole of the condyle, use of the visual analogue scale (VAS) and assessment of the range of mandibular movements.

\section{MATERIAL AND METHODS}

Forty patients with articular symptoms were selected from the TMJ Disorders Service at Ribeirão Preto Dental School, University of São Paulo based on a standardized and comprehensive clinical examination (12). The exclusion criteria were: use of medications for pain control, use of occlusal splint, and clinical conditions in which LLLT could be contra-indicated such as aggressive tumor and infections. The subjects were informed about the research purposes and signed 
an informed consent form approved by the Research Ethics Committee (Process \#2002.1.689.58.4). They were randomly divided into an treatment and a placebo group with 20 subjects each.

TMJ pain was quantified by the VAS, where 0 indicated "no pain" and 10 indicated "the worst possible pain", during palpation of the lateral pole of the condyle, and measurements of mouth opening, right and left lateral excursions were obtained in all evaluations by only one operator who was previously calibrated to do these procedures of same manner. The measurement of the mouth opening was made by use of a millimeter ruler that was placed at the incisal edge of the maxillary central incisor that is the most vertically oriented and measured vertically to the labioincisal edge of the opposing mandibular incisor. For measurement of the right and left lateral excursions, the patient was asked to bite, and a line corresponding to the midline between the upper incisors was drawn on the labial surface of the opposite lower incisor. Then, the patient was asked to move his/her mandible towards the right or left shoulder as far as possible. The examiner measured the point corresponding to the maximum lateral excursion of the lower midline (19). These evaluations were performed at the following time points: E1, before laser application; E2, immediately after each of 8 applications; the laser was applied twice a week during 4 weeks, as recommended by the World Association of Laser Therapy; E3, 7 days after the last application; and E4, 30 days after the last application.

The LLL used in the study was a GaAlAs laser source (Physiolux Dual P.5040; Bioset Industry of

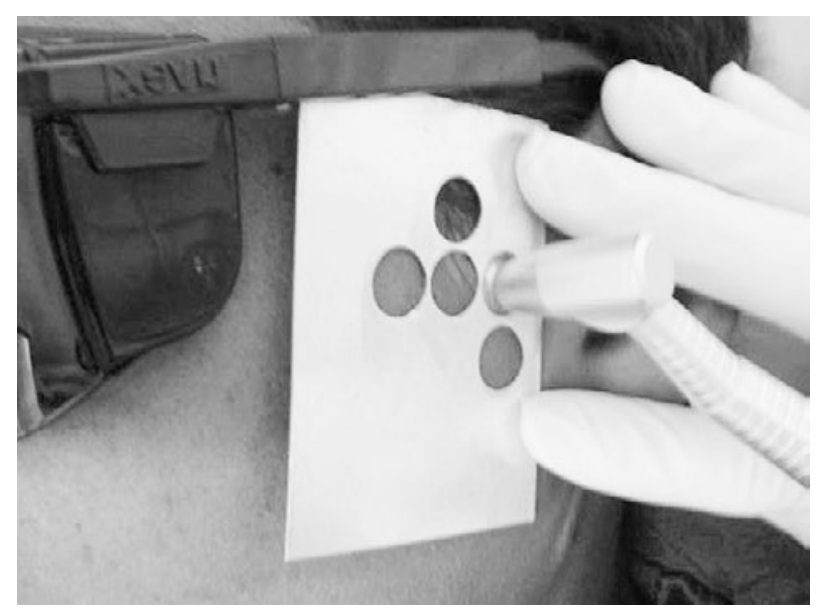

Figure 1. Illustration of the guide with standardized circular perforations used to demarcate the points for LLLT.
Electronic Technology Ltda., São Carlos, SP, Brazil) emitting a continuous laser beam (830 nm wavelength; $40 \mathrm{~mW}$ power output). The treated group received the effective dose $\left(5 \mathrm{~J} / \mathrm{cm}^{2}\right.$ per point, $\left.10 \mathrm{~s}\right)$ and the other group received a placebo application $\left(0 \mathrm{~J} / \mathrm{cm}^{2}\right.$ per point, $15 \mathrm{~s}$ ) on the affected points - superior, anterior, posterior, and posterior-inferior of the lateral pole of the condyle - which were demarcated bilaterally with a pencil, with the aid of a guide with standardized circular perforations (12) (Fig. 1).

After completion of the study, the patients of the placebo group were treated according to their individual needs and disorders, so that these subjects would not leave without treatment.

The mouth opening was registered before (E1), immediately after laser applications (E2), after 7 days (E3) and 30 days (E4).

Data obtained were subjected to parametric (ANOVA) and non-parametric (Kruskal-Wallis) statistical analysis. A significance level of $1 \%$ was set for all analyses.

\section{RESULTS}

Table 1 presents the mean values from VAS for pain symptoms of the pressured regions in the evaluations for the groups that received active and placebo doses, corresponding to right and left sides. This experimental design was submitted to statistical analysis by the Kruskal-Wallis test, which indicated significant difference $(p<0.01)$ between the groups and among the evaluations on both the right and left condyles.

Table 2 presents the mean values from the mouth opening measurements. This experimental design was submitted to statistical analysis by ANOVA and Tukey's

Table 1. Mean VAS values for pain symptoms of the pressured regions in the evaluations for the groups that received either an active laser dose or a placebo dose.

\begin{tabular}{lccccc}
\hline \multirow{2}{*}{ Evaluations } & \multicolumn{2}{c}{$\begin{array}{c}\text { Right lateral pole } \\
\text { condyle }\end{array}$} & & \multicolumn{2}{c}{$\begin{array}{c}\text { Left lateral pole } \\
\text { condyle }\end{array}$} \\
\cline { 2 - 3 } \cline { 5 - 6 } \cline { 5 - 6 } & Active & Placebo & & Active & Placebo \\
\hline E1 & 5.40 & 5.80 & & 6.45 & 6.25 \\
E2 & 2.10 & 4.45 & & 3.05 & 5.60 \\
E3 & 2.50 & 5.15 & & 2.50 & 5.60 \\
E4 & 2.95 & 5.60 & & 2.95 & 6.30 \\
\hline
\end{tabular}


test, which indicated no significant difference among the evaluations ( $p>0.01)$, but showed significant difference $(p<0.01)$ between the groups at the E4.

Table 3 shows the mean values of measurements of right and left lateral mandibular excursions. This experimental design were submitted to statistical analysis by Kruskal-Wallis test, which indicated statistically significant difference $(p<0.01)$ between the groups.

\section{DISCUSSION}

The initial treatment of TMD frequently focuses on the use of noninvasive pain control methods (20). LLLT was applied in this study as a noninvasive auxiliary therapy for pain control in patients with TMD. It has been employed as an agent that have biomodulatory, antiinflammatory and analgesic effects on physiological, cellular and systemic responses (12). LLLT has been considered effective in reducing pain and muscular tension, thus, improving the life quality of patients (12).

Analyzing the painful symptoms evaluations at the right and the left sides in the treated group, there was a significant difference from E1 to E2, suggesting the immediate effect of laser applications. However, no significant differences were observed between the following evaluations, confirming that LLLT was effective in attenuating the painful symptoms only during the 4-week application period. In the same way as observed in previous studies $(9,11)$, this positive result reinforces the biologic effects of laser therapy, such as increased pain tolerance due to changes in cellular membrane potency, vasodilatation, reduction of edema, increase in intracellular metabolism and acceleration of wound healing (12). However, in spite of being used for treating several conditions (15), LLLT effects depend on dosimetry and systemic corporal conditions (17).

In the group of patients that received the placebo

Table 2. The mean values from the measurements of mouth opening $(\mathrm{mm})$ in the evaluations for the groups that received either an active laser dose or a placebo dose.

\begin{tabular}{lcc}
\hline Evaluations & Active laser dose & Placebo dose \\
\hline E1 & 48.25 & 47.90 \\
E2 & 50.60 & 47.30 \\
E3 & 50.25 & 47.05 \\
E4 & 50.55 & 46.35 \\
\hline
\end{tabular}

dose, there was no significant reduction of painful symptoms from E1 to E2, and neither among E2, E3 and and E4. Therefore, the power of the placebo effect has not been demonstrated in the present study. The maintenance of pain at the later evaluations (E3 and E4) indicates that no placebo effect occurred in this research. These results differ from those of a previous investigation (10), which demonstrated significant pain reduction in both treatment and placebo groups, though with increased mandibular movement in the treated group only. In our study, the significant difference between the groups indicates that the active laser therapy promoted suitable effects.

Before the start of the applications, both groups received explanations about the study, as specified in the informed consent form. Thus, the placebo effect, widely discussed in another study (11) may have occurred even during the application period in the treated group. The same should be considered with respect to the effect of the examiner/patient relationship and the psychological effect of LLLT.

In this research, a significant improvement in the range of right and left mandibular movements was observed in the treated group when the results were compared between the groups at the final evaluation (E4). This suggests that the laser therapy was efficient in promoting an increase of mandibular movements in the patients that received the active laser dose following the proposed protocol. Similar results were found by others authors $(4,10)$. This is probably due to the analgesic effect of low-intensity lasers (3), which was demonstrated in this study by the decrease in the VAS scores (11). On the other hand, the placebo group did not show significant differences among the four evaluation time points, indicating the inefficacy of placebo applications for decrease of pain and improvement in the range of

Table 3. Mean values of measurements of right and left lateral excursion mandibular movements $(\mathrm{mm})$ in the evaluations for the groups that received either an active laser dose or a placebo dose.

\begin{tabular}{llllll}
\hline \multirow{2}{*}{ Evaluations } & \multicolumn{2}{c}{ Active laser dose } & & \multicolumn{2}{c}{ Placebo dose } \\
\cline { 2 - 3 } \cline { 5 - 6 } & Right & Left & & Right & Left \\
\hline E1 & 7.20 & 6.85 & & 6.85 & 6.15 \\
E2 & 8.95 & 9.05 & & 7.15 & 6.80 \\
E3 & 8.65 & 9.45 & & 6.85 & 6.90 \\
E4 & 9.25 & 9.70 & 6.75 & 6.70 \\
\hline
\end{tabular}


mandibular movements.

The LLLT was applied on the selected points considering the presence of nociceptors in the periarticular tissues (discal ligaments, capsular ligaments and retrodiscal tissues), because these structures are involved in the TMJ pain. Similar points were evaluated in other studies by some authors $(5,7,8)$. Internal derangement of TMJ is frequently associated with pain due the inflammatory disorders that occur when the collateral ligaments are extended or ruptured. Consequently, any mandibular movement that extends or compresses these tissues will induce an increase of pain, especially during muscular and articular palpations (3). The typical clinical finding in patients with TMJ dysfunction is the tenderness of the TMJ during palpation and mandibular lateral excursion (4). A considerable part of population groups studied present at least one sign or symptom of TMD (3), and the main complaint of patients with this dysfunction or the reason why they seek treatment is some type of joint or muscular pain (2).

Regarding the evaluation of TMD pain, much attention has been given to measuring the intensity of pain upon palpation of the masticatory muscles and TMJ. The VAS is also commonly used to measure pain in subjects with TMD $(4,5,8,14)$, and it was employed in this study to quantify the pain in the lateral pole of the condyle. The measurements of mandibular movements were applied as a functional tool to observe the outcomes on articular pain after effective and placebo laser applications.

The importance of investigating the actual analgesic efficacy of LLLT lies on the fact that TMD symptoms have been treated by a wide array of methods separately, such as interocclusal splint, medication, physical therapy and transcutaneous electric nerve stimulation (TENS); in most cases, however, better outcome is achieved when therapies are associated (3), and lasers can be of great value.

The successful treatment of pathologies in the maxillofacial region using LLLT has been demonstrated (6). Its use in the treatment of muscular and joint dysfunctions is due to its recognized analgesic effect, explained by the increase of beta endorphin level, increase of pain discharge threshold, decrease of bradykinin and histamine release, increase of lymphatic flow, decrease of edema and algesic substances, increase of blood supply, time reduction of inflammation, and promotion of muscle relaxation (4).

Like in any therapy, patients respond similarly to
LLLT. Patient response depend not only on the type of laser, but also on the target tissue and immunological system conditions. An unsatisfactory outcome can be due to very low doses, very high doses, incorrect diagnosis, small number of sessions, inadequate energy density, among others (17).

In this study, the range of mandibular lateral movements and the painful symptoms on the lateral pole of the condyle were evaluated in patients with TMD after LLLT to verify the efficacy of this therapy. The results showed that the laser therapy was effective in the improvement of the range of mandibular lateral movements and promoted a significant reduction of pain symptoms.

\section{RESUMO}

O objetivo deste estudo foi avaliar a eficácia da terapia com laser de baixa intensidade na melhora dos movimentos mandibulares e dos sintomas dolorosos em pacientes com disfunção temporomandibular(DTM). Quarenta pacientes foram aleatoriamente divididos em dois grupos $(\mathrm{n}=20)$ : Grupo 1 recebeu a dose efetiva (laser de AsGaAl $830 \mathrm{~nm}, 40 \mathrm{~mW}, 5 \mathrm{~J} / \mathrm{cm}^{2}$ ) e Grupo 2 recebeu a aplicação placebo $\left(0 \mathrm{~J} / \mathrm{cm}^{2}\right)$, no modo contínuo no pólo lateral do côndilo afetado: superior, anterior, e posterior-posterior e inferior, 2 vezes por semana, por 2 meses. Quatro avaliações foram feitas: A1 (antes da aplicação), A2 (imediatamente após a última aplicação), A3 (uma semana após a última aplicação) e A4 (um mes após a última aplicação). O teste estatístico de Kruskal-Wallis mostrou melhoras significativas $(p<0,01)$ nos sintomas dolorosos no grupo 1, diferentemente do grupo 2. Uma melhora significativa na extensão dos movimentos mandibulares foi observada quando os resultados foram comparados entre os dois grupos na A4. A aplicação do laser é uma terapia de suporte no tratamento da DTM, uma vez que resultou em imediata redução dos sintomas dolorosos e aumento na extensão dos movimentos mandibulares no grupo experimental. Os mesmos resultados não foram observados no grupo placebo.

\section{REFERENCES}

1. Hotta PT, Hotta TH, Bataglion C, Pavão RF, Siéssere S, Regalo SC. Bite force in temporomandibular dysfunction (TMD) and healthy complete denture wearers. Braz Dent J 2008;19:354-357.

2. Gremillion HA. The prevalence and etiology of temporomandibular disorders and orofacial pain. Tex Dent J 2000;117:30-39.

3. Fikácková $H$, Dostálová $T$, Vosická R, Peterová V, Navrátil L, Lesák J. Arthralgia of the temporomandibular joint and low-level laser therapy. Photomed Laser Surg 2006;24:522-527.

4. Núñez SH, Garcez AS, Suzuki SS, Ribeiro MS. Management of mouth opening in patients with temporomandibular disorders through low-level laser therapy and transcutaneous electrical neural stimulation. Photomed Laser Surg 2006,24:45-49.

5. Simunovic Z. Low level laser therapy with trigger points technique: a clinical study on 243 patients. J Clin Laser Med Surg 1996;14:163-167.

6. Conti PCR. Low level laser therapy in the treatment of 
temporomandibular disorders (TMD): a double blind pilot study. J Craniomandib Pract 1997;15:144-149.

7. Pinheiro ALB, Cavalcanti ET, Rego T, Pinheiro M, Manzi CT. Low power laser therapy in the management of disorders of the maxillofacial region. J Clin Laser Med Surg 1997;15:181-183.

8. Pinheiro ALB, Alves MJPC, Ramos E, Rolim AB, Vieira ALB. Is LLLT effective in the management of TMJ pain? Proceedings 6th International Congress on Laser in Dentistry. University of Utah Press 1998; 163-165.

9. Kobayashi M, Kubota J. Treatment of temporomandibular joint (TMJ) pain with diode laser therapy. J Laser Therapy 1999; 11.

10. Hotta TH, Bataglion A, Bataglion C, Bezzon OL. Involvement of dental occlusion and trigeminal neuralgia: a clinical report. J Prosthet Dent 1997;77:343-345.

11. Kulekcioglu S, Sivrioglu K, Ozcan O, Parlak M. Effectiveness of low-level laser therapy in temporomandibular disorder. Scand J Rheumatol 2003;32:114-118.

12. Mazzetto MO, Carrasco TG, Bidinelo EF, Pizzo RCA, Mazzetto RG. Low intensity laser application in temporomandibular disorders: a phase I double-blind study. J Craniomandib Pract 2007;25:186-192.

13. Wilder-Smith P. The soft laser: therapeutic tool or popular placebo? Oral Surg 1988;66:654-658.
14. Sandoval MC, Mattiello-Rosa SMG, Soares EG, Parizotto NA Effects of laser on the synovial fluid in the inflammatory process of the knee joint of the rabbit. Photomed Laser Surg 2009;27:1-7.

15. Hansen HJ, Thoroe U. Low power laser biostimulation of chronic oro-facial pain. A double-blind placebo controlled cross-over study in 40 patients. Pain 1990;43:169-179.

16. Cheethan MJ, Young RS, Dyson M. Histological effects of 820 $\mathrm{nm}$ laser irradiation on the healthy growth plate of the rat. Laser Therapy 1992;2:59-63.

17. Kubota J, Ohshiro T. The effects of diode laser low reactive level laser therapy (LLLT) on flap survival in a rat model. Laser Therapy 1989;1:127-135.

18. Tunér J, Hode L. Are all the negative studies really negative. Laser Therapy 1998;10:165-174.

19. Masumi S, Kim YJ, Clark GT. The value of maximum jaw motion measurements for distinguishing between common temporomandibular disorder subgroups. Oral Surg Oral Med Oral Pathol Oral Radiol Endod 2002;93:552-559.

20. Ingawale $\mathrm{S}$, Goswami T. Temporomandibular joint: disorders, treatments, and biomechanics. Ann Biomed Engineering. 2009;37:976-996.

Accepted June 6, 2010 